\title{
Study of equatorial Kelvin waves using the MST radar and radiosonde observations
}

\author{
P. Kishore ${ }^{1}$, I. V. Subba Reddy ${ }^{2}$, S. P. Namboothiri ${ }^{1}$, K. Igarashi ${ }^{1}$, M. Venkat Ratnam ${ }^{3}$, D. Narayana Rao $^{4}$, and \\ S. Vijaya Bhaskara Rao ${ }^{2}$ \\ ${ }^{1}$ National Institute of Information and Communications Technology, Tokyo, Japan \\ ${ }^{2}$ Department of Physics, Sri Venkateswara University, Tirupati 517 502, India \\ ${ }^{3}$ Research Institute for Sustainable Humanosphere, Kyoto University, Uji, Kyoto 611-0011, Japan \\ ${ }^{4}$ National MST Radar Facility, Department of Space, Gadanki 517 112, Tirupati, India
}

Received: 15 July 2004 - Revised: 17 February 2005 - Accepted: 24 February 2005 - Published: 3 June 2005

\begin{abstract}
In this paper an attempt has been made to study equatorial Kelvin waves using a high power coherent VHF radar located at Gadanki $\left(13.5^{\circ} \mathrm{N}, 79.2^{\circ} \mathrm{E}\right)$, a tropical station in the Indian sub-continent. Simultaneous radiosonde observations taken from a nearby meteorological station located in Chennai $\left(13.04^{\circ} \mathrm{N}, 80.17^{\circ} \mathrm{E}\right)$ were also used to see the coherence in the observed structures. These data sets were analyzed to study the mean winds and equatorial waves in the troposphere and lower stratosphere. Equatorial waves with different periodicities were identified. In the present study, particular attention has been given to the fast Kelvin wave (6.5-day) and slow Kelvin wave (16-day). Mean zonal wind structures were similar at both locations. The fast Kelvin wave amplitudes were somewhat similar in both observations and the maximum amplitude is about $8 \mathrm{~m} / \mathrm{s}$. The phase profiles indicated a slow downward progression. The slow Kelvin wave (16-day) amplitudes shown by the radiosonde measurements are a little larger than the radar derived amplitudes. The phase profiles showed downward phase progression and it translates into a vertical wavelength of $\sim 10$ $12 \mathrm{~km}$. The radar and radiosonde derived amplitudes of fast and slow Kelvin waves are larger at altitudes near the tropopause $(15-17 \mathrm{~km})$, where the mean wind attains westward maximum.
\end{abstract}

Keywords. Meteorology and atmospheric dynamics (Middle atmosphere dynamics; Tropical meteorology; Waves and tides)

\section{Introduction}

Extensive studies of large-scale Kelvin waves and Rossby gravity waves in the middle atmosphere have been carried

Correspondence to: P. Kishore

(kishore@nict.go.jp) out over the past three decades. Many theoretical and observational studies show that Quasi-Biennial Oscillation (QBO) and Semi-Annual Oscillation (SAO) dominate the large-scale dynamics of the equatorial middle atmosphere (Lindzen and Holton, 1968; Holton and Lindzen, 1972). The Kelvin waves have been observed in data obtained through various techniques including rocket and satellites. Analysis of the satellite wind data (Hirota, 1978; Salby et al., 1984; 1990) and temperature along with tracer species data (Randel, 1990) has shown evidence for Kelvin wave activity in the middle atmosphere. Using radiosonde data from Canton Island, Wallace and Kousky (1968) showed evidence of large-scale Kelvin waves in the stratosphere. They reported increased Kelvin-wave variance accompanying the descent of the westerly phase of the QBO, with the largest amplitudes occurring in the westerly shear zone. Equatorial wave characteristics have been reported in several studies (Salby et al., 1984; Dhaka et al., 1995; Krishna Murthy et al., 2002; Fujiwara et al., 2003) using temperature observations. Tsuda et al. (1994a,b) conducted an observational campaign for 24 days in Watukosek, Indonesia $\left(7.6^{\circ} \mathrm{S}, 112.7^{\circ} \mathrm{E}\right)$. In the lower stratosphere, fluctuations with periods of 7 and 20 days, having large amplitudes of up to 15 and $7 \mathrm{~m} / \mathrm{s}$, respectively, have been reported from their study. It is found that the Kelvin waves were conspicuously enhanced in a narrow region of about $5 \mathrm{~km}$, centered at the tropopause. Using both rocket and balloon wind data Dhaka et al. (1995) reported the existence of Kelvin waves with periods 12-16 days in the lower stratosphere. These waves showed downward phase progression with an average vertical wavelength of $10 \mathrm{~km}$. More recently, Krishna Murthy et al. (2002), using radar and Lidar data, identified equatorial slow Kelvin waves with different periodicities from 6-16 days in the troposphere and stratosphere regions. They found that equatorial waves modulate tropical tropopause temperature and altitude. 
Table 1. Experiment specification file (ESF) used for the present study of the Indian MST radar observation.

\begin{tabular}{ll}
\hline Parameter & Specification \\
\hline Pulse width: & $16 \mu \mathrm{s}$ \\
Inter-pulse period: & $1000 \mu \mathrm{s}$ \\
Coded/uncoded: & coded \\
No. of beams: & $5(\mathrm{E} 10 \mathrm{y}, \mathrm{W} 10 \mathrm{y}$, Zenith, N10x, S10x $)$ \\
Coherent integration: & 128 \\
No. of FFT points: & 128 \\
Nyquist frequency: & $\pm 4 \mathrm{~Hz}$ \\
Doppler resolution: & $0.06 \mathrm{~Hz}$ \\
Incoherent integration: & 1 \\
\hline
\end{tabular}

The knowledge of Kelvin waves is very important as they strongly modulate the tropopause structure, including the tropopause height, minimum temperature, and atmospheric stability. Kelvin waves also contribute significantly to the middle atmospheric dynamics. In the present study, characteristics of Kelvin waves were studied using MST radar and radiosonde observations. The database and the methodology adopted are briefly discussed in Sect. 2 . The amplitude and phase characteristics of different periodic components of the wind are discussed in Sect. 3, and finally, the overall summary and conclusions drawn from the present study are presented in Sect. 4.

\section{Observations and data analysis}

The Indian MST radar located at Gadanki $\left(13.5^{\circ} \mathrm{N}, 79.2^{\circ} \mathrm{E}\right)$ is a high power VHF phased array radar operating at $53-\mathrm{MHz}$ coherent backscatter mode with an average power aperture product of $7 \times 10^{8} \mathrm{Wm}^{2}$. The phased antenna array consists of $1024(32 \times 32)$ crossed 3-element Yagi antennas occupying an area of $130 \times 130 \mathrm{~m}$. The radiation pattern of the array provides a main beam with a $3^{\circ}$ two-way beam width and the first side lobe level of $-20 \mathrm{~dB}$. The radar beam can, in principle, be positioned at any look angle within $\pm 20^{\circ}$, but it is currently programmed to position at five look angles, zenith, $\pm 10^{\circ}$ off-zenith in the east-west and north-south directions. The complete time series of the decoded and integrated signal samples are subjected to FFT for the on-line computation of the Doppler power spectra for each range bin. The off-line data processing involves the removal of the dc component, an estimation of the average noise level, incoherent integration, the removal interference, if any, and the estimation of the three low-order moments. The three moments represent the signal strength, the weighted mean Doppler shift, and half-width parameters of the spectrum. For the estimation of noise level, the objective method developed by Hildebrand and Sekhon (1974) has been adopted here. To determine the wind components we have used the least-squares method as described by Sato (1989). Complete details of the system description and the signal processing are well described elsewhere (Rao et al., 1995; Kishore, 1995).

In the present study observations of the winds in the 3.6$20 \mathrm{~km}$ height region for the period June-August 1996 are utilized. These three months are generally considered as the typical monsoon season in India. The observations are daily evening common mode measurements for about $\sim 50 \mathrm{~min}$ at around 17:00 IST. The various experimental specifications used by the radar for the present study are given in Table 1 . Daily Doppler spectra corresponding to the five beams are obtained in the height range of $3.6-20 \mathrm{~km}$ at $150 \mathrm{~m}$ intervals. The observations were carried out coincidentally with the radiosonde observations at Chennai $\left(13.04^{\circ} \mathrm{N}, 80.17^{\circ} \mathrm{E}\right)$, which is about $100 \mathrm{~km}$ away from the radar site. The height resolution of the radiosonde data varies from $200 \mathrm{~m}$ at lower heights to $300 \mathrm{~m}$ at higher altitudes. We have interpolated the radiosonde data to $150-\mathrm{m}$ range resolution by applying the spline interpolation method. This makes both data sets with matching height resolution and hence the comparison is more meaningful.

Using the data (about one hour per day) we have constructed the mean and we call it daily mean. We understand that it is not at all realistic to consider it as the real daily mean. However, for the sake of easiness we continue the usage of the word "daily mean". The data were collected around the same time everyday and hence they collectively give a better picture of the wind pattern at that time slot. One deficiency of using this so-called daily mean is that we could not extract the real daily variations and their potential impact to the present investigation. This could be done in a future study in which we plan to investigate the planetary wave activities using the radar data alone.

As mentioned previously, the observations were conducted during the monsoon season. It is generally known that largescale, low frequency forcings associated with the monsoons generate Rossby and Kelvin waves along the equator. However, details of such effects are beyond the scope of the present study.

The daily mean winds were examined and it was found that there were small data gaps, which are filled with linear interpolation. The Lomb-Scargle (L-S) periodogram analysis method (Scargle, 1982) of spectral analysis is used for the determination of the fast Kelvin (6.5-day) and slow Kelvin (16-day) wave amplitude and phase. Scargle's definition of the time-translation invariance of the periodogram is exactly equivalent to a least-squares fitting of the sine wave to data. Compared to the other methods, the L-S method weights the data per point, instead of per time interval. Also, the L-S periodogram can provide an estimate of the significance of each peak by examining the probability of its arising from a random fluctuation (Luo et al., 2002; Namboothiri et al., 2002).

A filter of band-pass in nature is necessary for indicating a possible wave activity in the time domain. For the present study, the simple and convenient method of the inverse transform of the Fourier analysis is used. The method involves applying the Fourier transform (FT) to a segment 

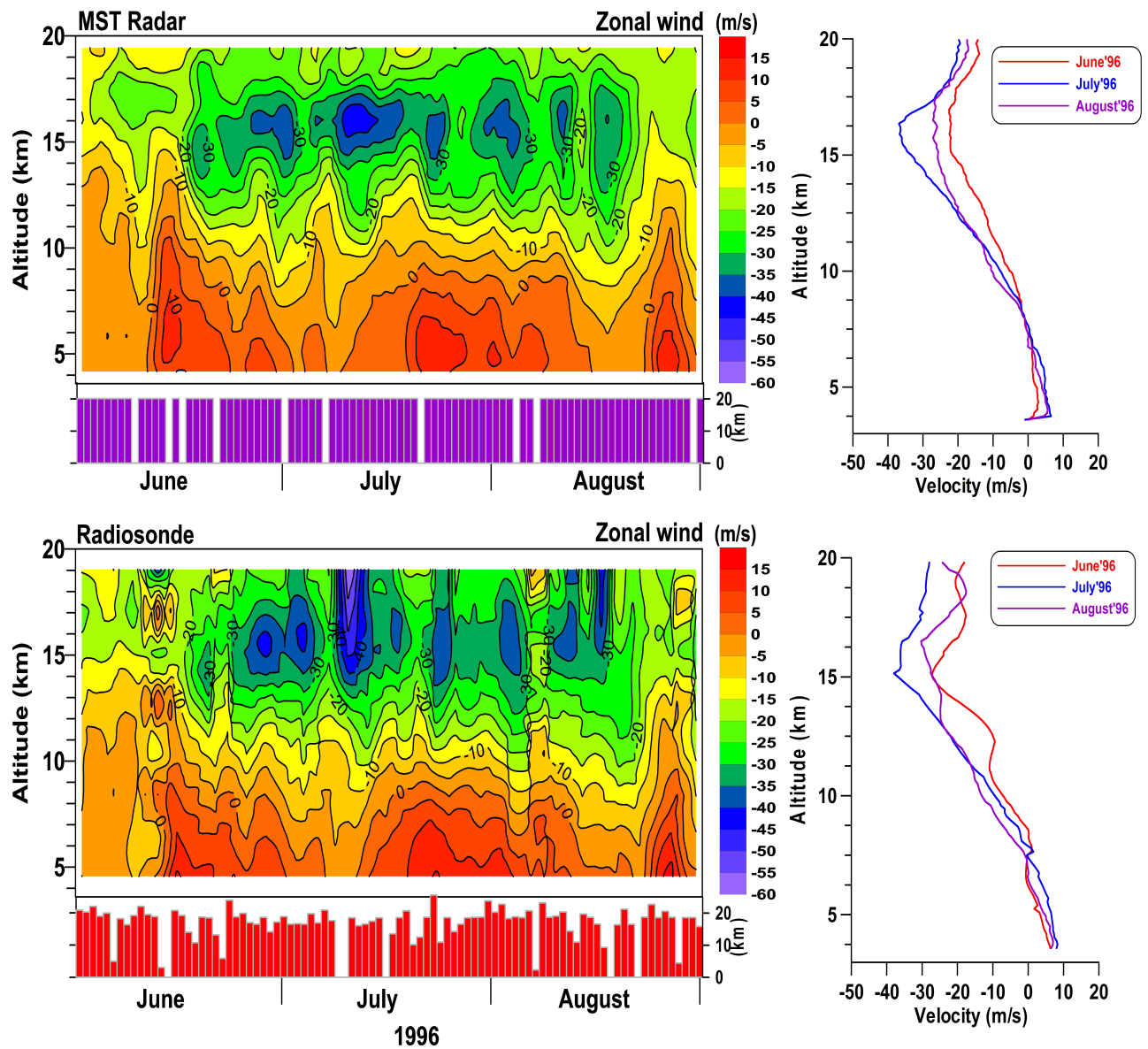

Fig. 1. Height-time contours of mean zonal winds at MST radar and radiosonde observation sites for the period of June-August, 1996. Bar diagrams shown below the contour plots indicate the data availability during this period. The profiles in the right panels depict the monthly mean values.

(window) of data (data length), multiplying the output by a filter function (bandwidth) and then doing an inverse FT to get back a filtered data set in the time domain. For the 6.5day wave, high and low cut-off frequencies are selected as 0.2 and $0.125 \mathrm{cpd}$ (cycles per day), which corresponds to 5 and 8 days and for the 16-day wave, the cut-off frequencies are 0.1 and $0.045 \mathrm{cpd}$, which corresponds to the 10 and 22 days, respectively.

\section{Results and discussion}

Before going into the details of the Kelvin waves observed, it is desirable to discuss the background features at the respective observational sites. Figure 1 shows the time-height sections of the zonal winds observed at the Indian MST radar site and the balloon wind measurement site at Chennai during the monsoon season of the year 1996. Daily mean values are utilized to develop these wind contours. On the right-hand side of the figure the vertical profiles of the monthly mean winds are also shown. Describing the radar results first, it can be seen that below about $7 \mathrm{~km}$, winds are mostly eastward in direction and above that there is westward flow through- out the season. The maximum eastward wind is observed to be about $10 \mathrm{~m} / \mathrm{s}$. The maximum westward wind is in the range of $40 \mathrm{~m} / \mathrm{s}$ and its occurrence is at around $16 \mathrm{~km}$ (near the tropopause) in July. The balloon measurements shown in the lower panel depict some differences as well as similarities with the radar measurements. The maximum eastward wind has an average strength of $10 \mathrm{~m} / \mathrm{s}$ and its occurrence is at around $\sim 6 \mathrm{~km}$. It can be seen that the wind pattern observed at both the sites are generally the same. The height occurrence of summer westward maxima is at around $16 \mathrm{~km}$ in both radar and balloon wind observations and also its time occurrence is in July. The height profiles in the right panel exhibit similar monthly mean wind values.

Figure 2 shows typical amplitude spectra (zonal component) obtained for four selected altitudes 5.4, 9.3, 13.2, and $17.1 \mathrm{~km}$ observed by the radar (left panel) and balloon (right panel) measurements. The amplitudes are calculated by using the Lomb-Scargle periodogram analysis. The length of the window was taken to be 56 days (9 June to 3 August). Periodogram analysis conducted for the time series from various altitudes reveals prominent components centered at 6.5 days (fast Kelvin wave) and 16 days (slow Kelvin wave). The 

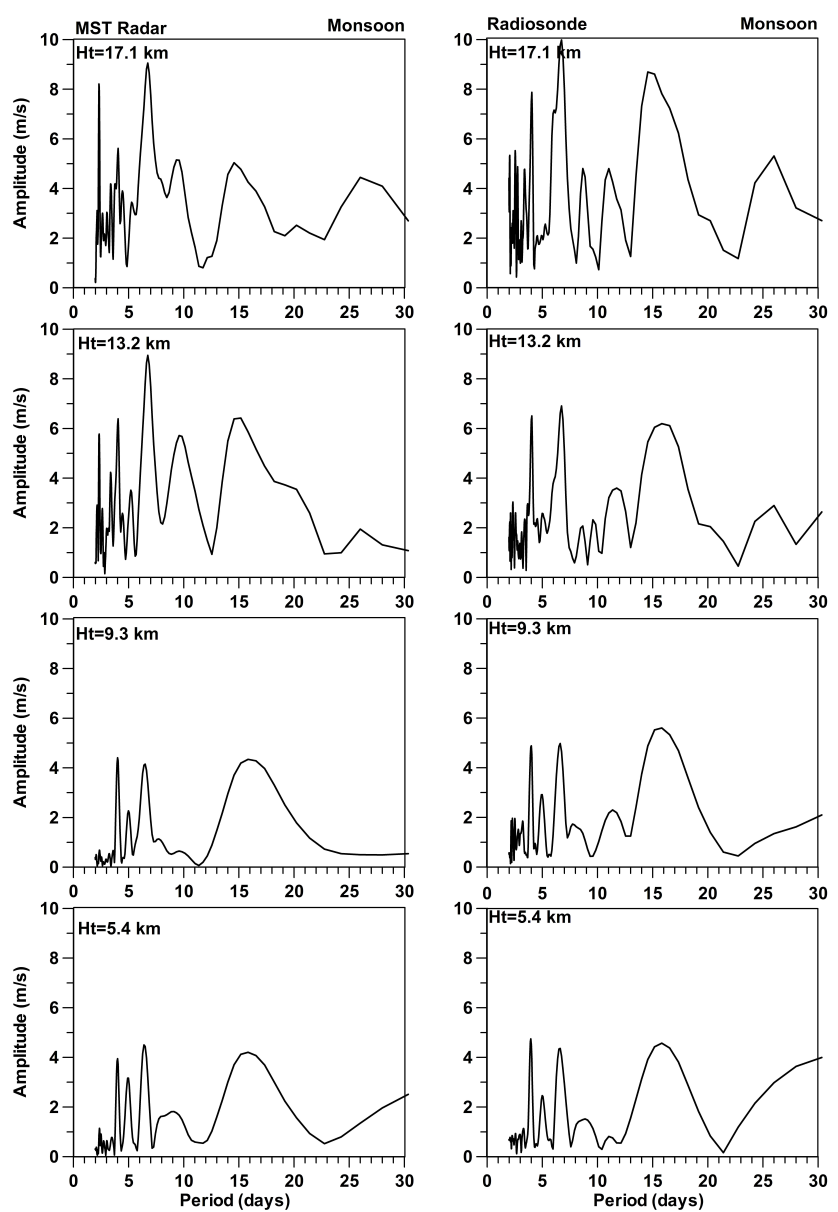

Fig. 2. The spectral amplitudes of the zonal wind in the interval 9 June-3 August 1996 measured at four different altitudes (5.4, 9.3, 13.2 and $17.1 \mathrm{~km}$ ) at MST radar (left) and radiosonde (right) sites.

16-day peak is broad, extending over roughly 12 to 22 days. The 6.5- and 16-day spectral peaks become larger at higher altitudes than compared to the lower altitudes. This feature is evident in both measurements, except for the radar measurements of the 16-day wave at $17.1 \mathrm{~km}$. By calculating the area between the $90 \%$ significance level and the calculated spectral amplitude, the centroid of the spectral peak was determined. At all four sampled heights and throughout the entire period the fast and slow Kelvin waves were present and they showed similar spectral structures. Further, there is an indication of variability with periodicities near 3.6 and 5 days. However, these ultra fast Kelvin waves are out of scope of the present study.

The zonal amplitude spectra of the 6.5-day wave activity as a function of height and time, observed by the radar and balloon wind measurements, are shown in Fig. 3. The top panel corresponds to the radar and the bottom panel represents the balloon measurements. The spectral amplitudes in the contour plots are calculated by a Lomb-Scargle periodogram analysis within a set time window of 30 days in length. This window was shifted by a step of 5 days, and the power spectral amplitude and phase values are estimated.
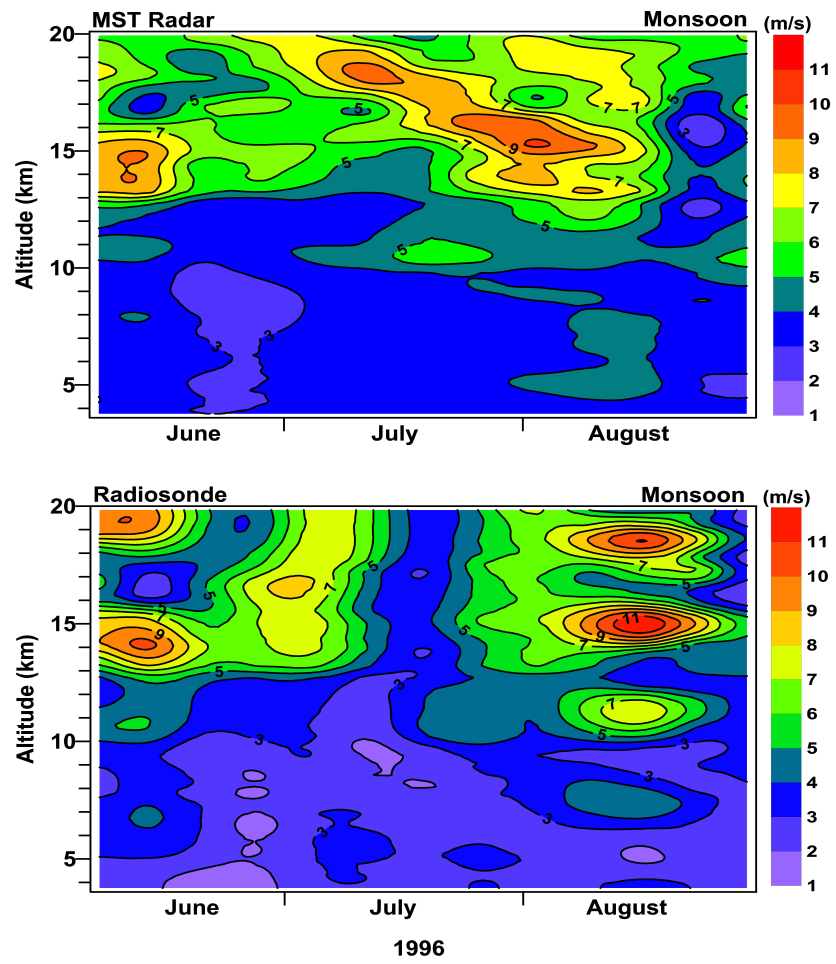

Fig. 3. Amplitudes of the zonal component of the 6.5-day wave obtained by Lomb-Scargle periodogram analysis during the monsoon season at the MST radar (top) and radiosonde (bottom) observation sites.

In the process, the confidence levels of the periodograms are estimated for only those spectral peaks with more than $90 \%$ significance. The 6.5-day wave amplitudes observed at both locations have some similarities as well as differences. Above $13 \mathrm{~km}$ the wave activity attains its maximum. In the case of radar data the wave amplitudes reach maximum values during mid-July to mid-August. The wave amplitude attains $9-10 \mathrm{~m} / \mathrm{s}$ at $15-17 \mathrm{~km}$. In the balloon data, the maximum amplitudes are observed in August. The peak amplitudes $(10-12 \mathrm{~m} / \mathrm{s})$ are clearly identified at two height regions, one near $16-17 \mathrm{~km}$ and another at $19 \mathrm{~km}$. In July the balloon derived amplitudes are weaker than the radar determinations. In both observations the amplitudes have a maxima near the tropopause level. Assuming that zonal wind oscillations are due to Kelvin wave mode, these waves are eastward propagating equatorial waves. It has been shown that the Kelvin wave amplitudes have maximum whenever the westward flow becomes stronger. The above statement is valid for the present observation of the fast Kelvin wave. As seen in the figure, radar observations show maximum amplitudes at $13-18 \mathrm{~km}$ where the winds show the westward maximum (Fig. 1).

To deduce more information on the height dependence of the 6.5-day wave, in Fig. 4 the monthly amplitudes and phases obtained by the radar and balloon measurements are shown. The amplitudes and corresponding phases are considered only when they are $>90 \%$ significant. The height 
profiles of the amplitude show some features more prominently than that seen in the contour plots (Fig. 3). In general, the amplitudes and phases observed by the radar and balloon closely resemble each other. Both the radar and balloon measurements show almost identical amplitudes in June. In July, below $15 \mathrm{~km}$ altitude the amplitudes of the radar and balloon measurements were similar, and in the $15-19 \mathrm{~km}$ range the radar amplitudes became larger than the balloon derived amplitudes. Comparatively large fluctuations were seen in the amplitudes derived by radiosonde observations during $\mathrm{Au}$ gust. The phase profiles indicated a fairly slow downward progression below $16 \mathrm{~km}$ in both measurements. The average vertical wavelength in both stations is obtained as 10$12 \mathrm{~km}$. The values of the vertical wavelength are consistent with those reported earlier for the Indian MST radar location (Dhaka et al., 1995). Rocket and satellite observations had found significant $\sim 7$-day wave activity in the stratosphere when the background winds were westward (Hirota, 1979; Hitchman and Leovy, 1986; Canziani and Holton, 1995). Using numerical simulations Miyoshi (1999) found that the enhancement of the 5-day wave in the mesopause region occurs simultaneously with that in the stratosphere.

To illustrate the features of the 6.5-day oscillations at different heights from 4 to $20 \mathrm{~km}$, the zonal wind data set of length 20 days has been subjected to a band-pass filter of width 5-8 days. This band-pass is wide enough to isolate the phenomena over a broad period range centered at 6.5-days. The height averages ( 8 range bins, $1.2 \mathrm{~km}$ ) of the winds are used as the input to the filter and the results are displayed in Fig. 5. Results of a similar analysis conducted for the balloon data are shown in the right panel of the figure. It is apparent that there is 6.5-day wave activity during most of the monsoon season. At both stations the wave activity maximizes near tropopause level. The observed amplitudes at the balloon site are larger than the amplitudes at the radar site. The analysis conducted for the meridional component (figure not shown) indicate that the zonal amplitudes are larger than the meridional amplitudes. This is consistent with the other measurements at equatorial sites.

Now we proceed to a similar analysis conducted for the 16-day oscillations. Figure 6 presents the zonal amplitudes of the 16-day waves in the troposphere and lower stratosphere as observed by the radar and balloon wind measurements during the monsoon season of the year 1996. The amplitudes are calculated by using sliding periodograms applied to a window width of 30 days. The window was shifted by a step of 3 days, and the power spectral amplitude and phase values are estimated. In general, strong 16-day wave activity occurs mostly in the higher altitudes in both measurements. In the case of radar, above $12 \mathrm{~km}$ the 16-day wave activity increases up to $18 \mathrm{~km}$ and above this level the wave activity is found to recede throughout the season. The maximum amplitudes of about $8 \mathrm{~m} / \mathrm{s}$ are observed near $15-17 \mathrm{~km}$. In the balloon data the maximum amplitudes are observed in the month of July and August and it reaches a maximum of $10 \mathrm{~m} / \mathrm{s}$. Mostly the maximum amplitudes observed by the balloon measurements are slightly larger $(2-3 \mathrm{~m} / \mathrm{s})$ than
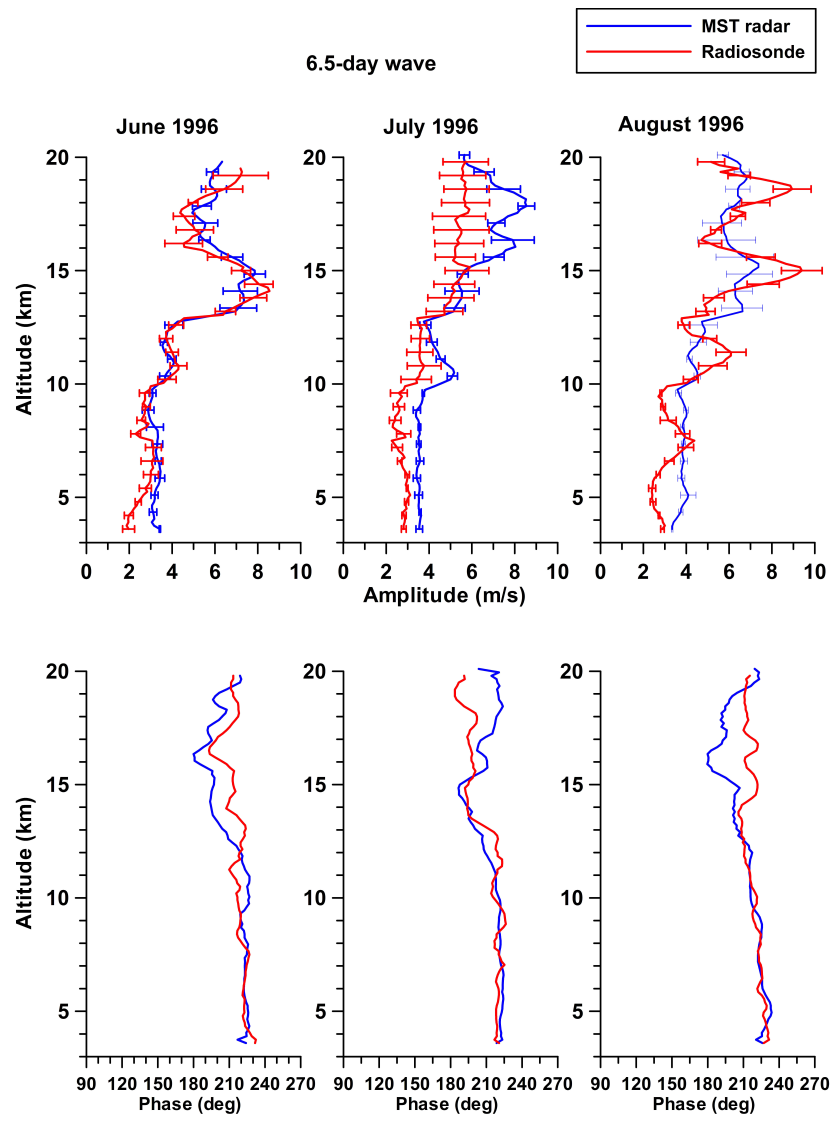

Fig. 4. Monthly profiles of amplitude (top panel) and phase (bottom panel) of the 6.5-day wave at MST radar and radiosonde observation sites during the monsoon season of 1996.
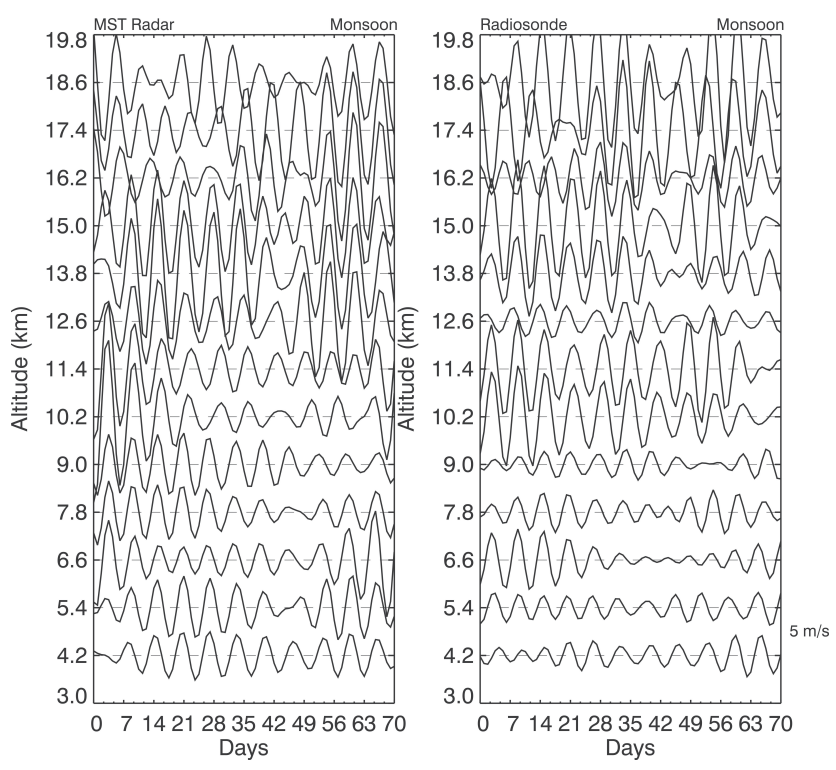

Fig. 5. Band-pass filtered (5-8 days) zonal winds for the near 6.5day oscillations at MST radar (left) and radiosonde (right) sites during 10 June-19 August 1996. 

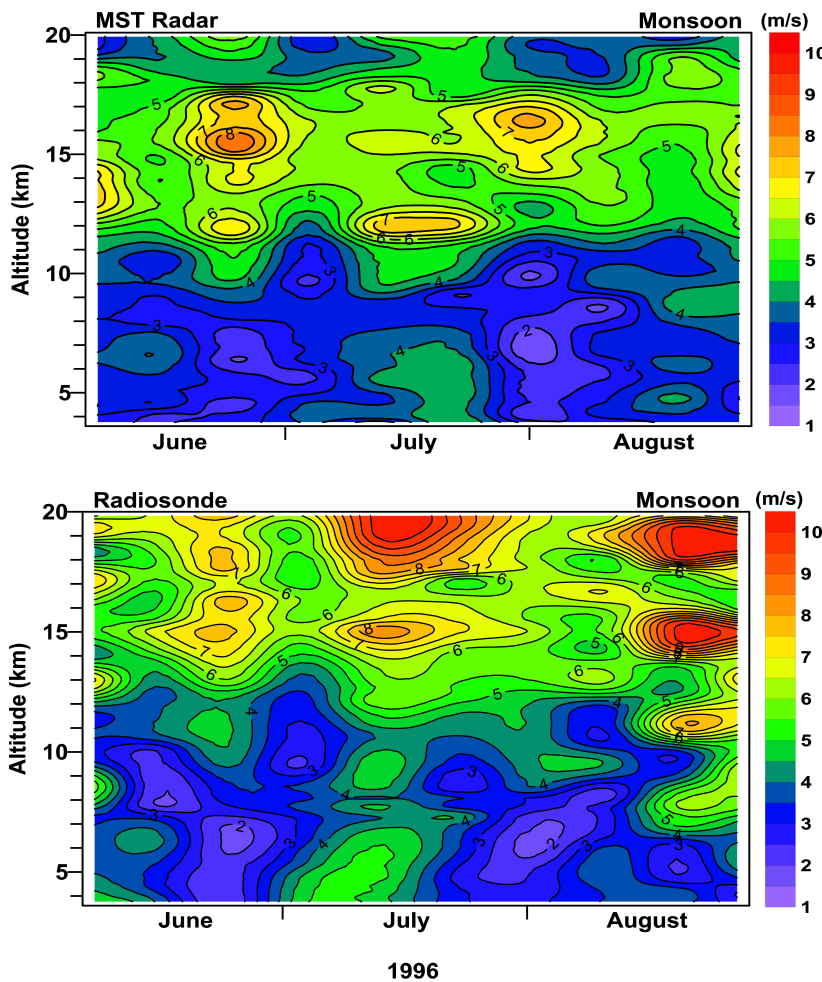

Fig. 6. Contour plots for the amplitudes of the 16-day wave obtained by Lomb-Scargle periodogram analysis during the monsoon season of 1996 at MST radar (top) and radiosonde (bottom) observation sites.

those by the radar measurements. In July and August the occurrence of maximum amplitudes shows some difference between the two measurements and thus makes the wave activity out of phase at these locations. More analysis based on a wider database is required to consolidate the causes behind such variations between these two nearby stations. The balloon wind measurements at Trivandrum $\left(8.5^{\circ} \mathrm{N}, 77^{\circ} \mathrm{E}\right)$ have observed 12-16-day period oscillations in the height range $16-24 \mathrm{~km}$ and they were considered as the manifestation of Kelvin waves (Dhaka et al., 1995), and the maximum amplitude observed near $15-17 \mathrm{~km}$ was about $6 \mathrm{~m} / \mathrm{s}$. Maximum amplitudes observed in the present study are larger than the observations reported for Trivandrum.

Figure 7 shows the height profiles (monthly mean) of the 16-day wave amplitudes and phases observed in the zonal component. Similar to the case of the 6.5-day wave, the amplitudes and the corresponding phases are considered only when they are $>90 \%$ significant. The wave occurrence was first identified and then the corresponding wave period was determined. Describing the monthly variations, amplitudes are generally $\sim 7 \mathrm{~m} / \mathrm{s}$ in all monsoon months at the $13-17 \mathrm{~km}$ height range. Comparing with the balloon measurements, below $17 \mathrm{~km}$ both amplitudes show good similarity in their structure. However, above $17 \mathrm{~km}$ the balloon amplitudes are larger than the radar derived amplitudes. In the phase profiles shown in the bottom panel we can see some similarities
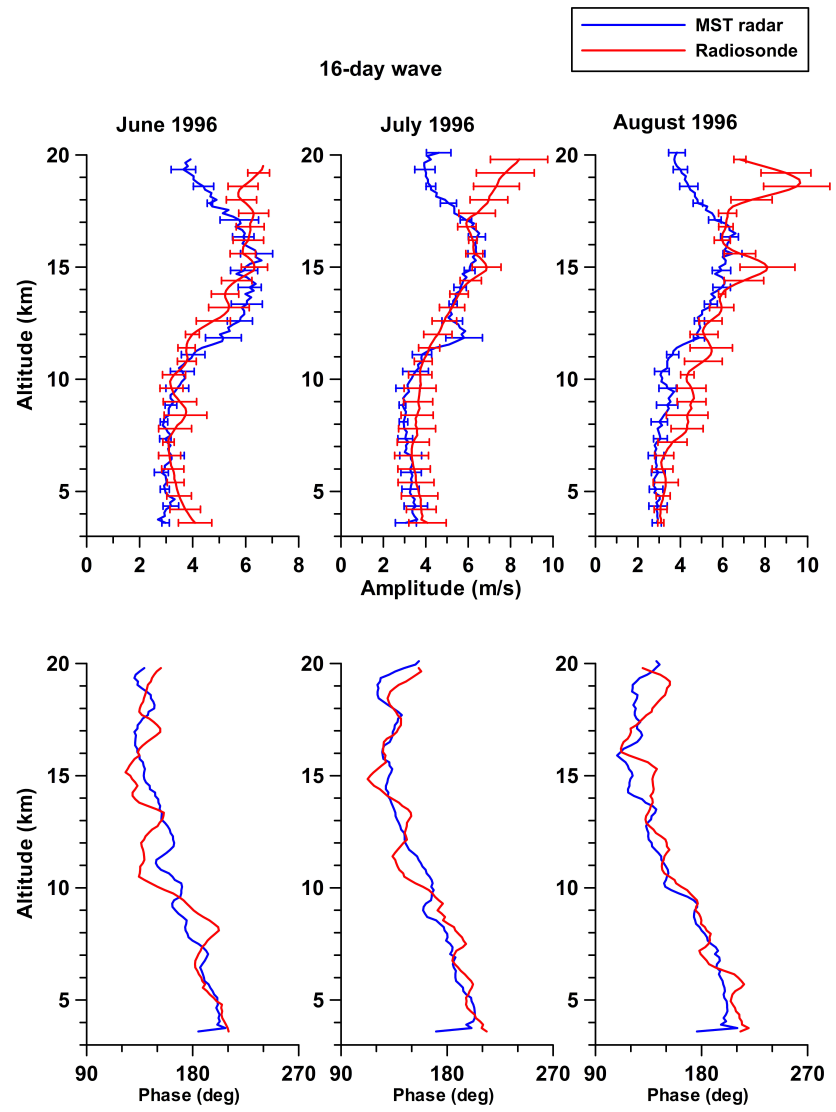

Fig. 7. Monthly profiles of amplitude (top panel) and phase (bottom panel) of the 16-day wave at MST radar and radiosonde observation sites during the monsoon season of 1996.

between the two measurements. This suggests that both observations involve the same wave events. The phase profiles show downward phase progression in the height regions 4 $17 \mathrm{~km}$ and above this level such a trend ceases. Tsuda et al. (1994a) observed waves with periods of 15-17 days in the troposphere and lower stratosphere. They found maximum zonal amplitude up to $7 \mathrm{~m} / \mathrm{s}$ and noted that the Kelvin wave was enhanced only in a narrow region with a thickness of about $5 \mathrm{~km}$ centered at the tropopause.

Figure 8 shows the results of the band-pass filtered zonal wind components of the radar and balloon wind measurements. Here we show different height layers of $1.2 \mathrm{~km}$ in thickness, in the troposphere and lower stratosphere. The data are height-averaged before applying the filter. The bandpass filter was applied with a window of 48 days and a bandwidth of 10-22 days to the daily zonal mean winds measured by the radar and balloon observations. There is a tendency to have larger amplitudes in the upper altitudes in both observations. One should remember that the filtered amplitude might be suppressed due to the transition band effect around the cut-off frequencies. In both data sets the filtered zonal component oscillates systematically with a period of $15-17$ days. In the balloon measurements, oscillation above $17 \mathrm{~km}$ is rather long and irregular. The amplitudes of radar and 
Table 2. Characteristics of equatorial waves.

\begin{tabular}{|c|c|c|c|c|c|c|}
\hline Period (days) & Type & $\begin{array}{l}\text { Height } \\
\mathrm{km}\end{array}$ & $\begin{array}{l}\text { Max. } \\
\text { range } \\
\text { radar }\end{array}$ & $\begin{array}{l}\text { amplitude } \\
(\mathrm{m} / \mathrm{s}) \\
\text { balloon }\end{array}$ & $\begin{array}{l}\text { Vertic } \\
(\mathrm{km}) \\
\text { radar }\end{array}$ & $\begin{array}{l}\text { al wavelength } \\
\text { balloon }\end{array}$ \\
\hline 6.5 day & Fast Kelvin wave & $4-20$ & $7-9$ & $7-9$ & $\sim 12$ & $\sim 10$ \\
\hline 16 day & Slow Kelvin wave & $4-20$ & $6-8$ & $8-10$ & $\sim 11$ & $\sim 12$ \\
\hline
\end{tabular}

balloon measurements are larger in upper altitudes, when the equatorial easterlies are prevailing. The wave activity noticed in this study may have a close connection to the intensity of the equatorial westward wind. It may be further noticed that the wave activity is not well correlated between the sites. Except for the first three or four height bins in the lower troposphere, the wave patterns show noticeable differences in their amplitude and period. A detailed look into such issues can be addressed only with a better data set. We should admit that the present database of $1 \mathrm{~h} /$ day is only suitable for an overall investigation of the wave signatures at both locations.

The observed differences between the radar and radiosonde results can be attributed to some other factors. It is well known that under mountain wave activity, which can be highly localized, large discrepancies can occur at lowerstratospheric altitudes. Radiosondes can drift horizontally more than $100 \mathrm{~km}$ from their launch site by the time they reach an altitude of $15 \mathrm{~km}$. Hence, the data are not necessarily representative of the atmosphere above the launch site. Some related discussion can be seen in the paper by Hooper et al. (2004).

Finally, Table 2 shows the comparative features of the wave characteristics of the fast Kelvin and slow Kelvin waves measured by the radar and radiosonde observations. It can be seen that the 6.5-day wave amplitude (maximum) measured by both measurements is same and the vertical wavelengths differ by a small amount. A roughly similar trend is observed in the case of the 16-day wave as well. Here the wave amplitudes show a maximum difference of $2 \mathrm{~m} / \mathrm{s}$ between the two measurements.

\section{Conclusions}

The focus of the present analysis was the study of a fast Kelvin wave (6.5-day) and a slow Kelvin wave (16-day), observed in the troposphere and lower stratosphere over a tropical site using radar and balloon wind measurements. We have used the wind data collected simultaneously by the MST radar located at Gadanki and the radiosonde observations at Chennai, a nearby station. In the present analysis data collected during the monsoon season (June-August) of 1996 have been sampled. Comparison of the radar and radiosonde winds agrees generally well in their pattern and strength. The 6.5-day wave amplitudes of radar and balloon profiles are somewhat similar and the maximum am-
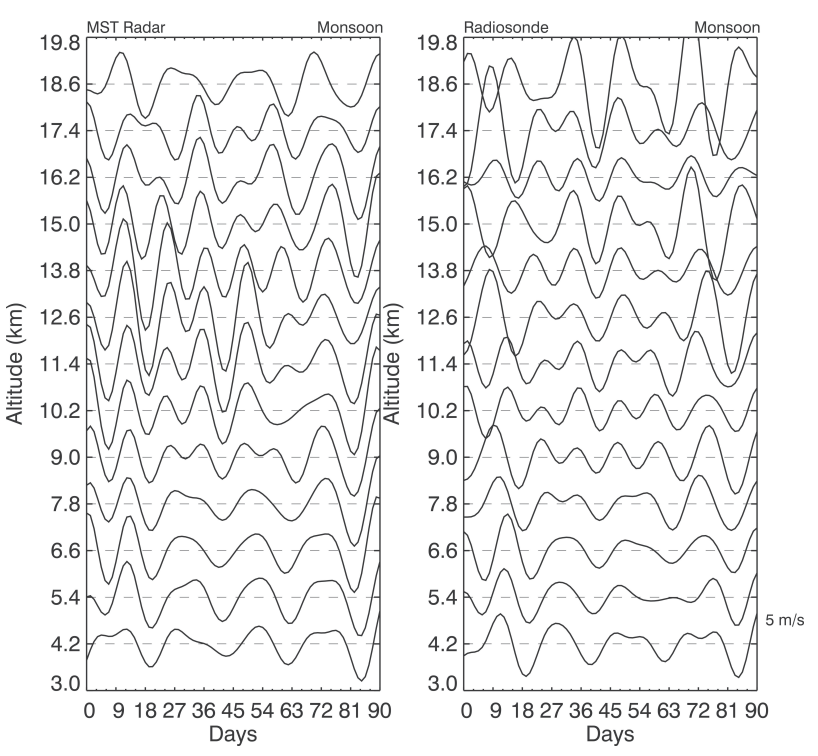

Fig. 8. Band-pass filtered 16-day oscillations at different altitudes at MST radar (left) and radiosonde (right) sites during the monsoon season of 1996.

plitude observed in each measurement is about $8 \mathrm{~m} / \mathrm{s}$. The amplitudes attain maximum values near the tropopause (15$17 \mathrm{~km}$ ) level in both the measurements. The phase profiles showed fairly downward progression and the estimated vertical wavelength is about $10-12 \mathrm{~km}$.

It is further found that the slow Kelvin wave (16-day) in both measurements exhibits large amplitudes $(7 \mathrm{~m} / \mathrm{s})$ near the tropopause level. The general structures observed by the radar and radiosonde observations are fairly similar. The radar and balloon derived zonal amplitudes are comparatively larger in the upper altitudes, when the equatorial easterlies are prevailing. The observed results show good qualitative and partly quantitative agreement with earlier observations on equatorial waves.

Additionally, it should be mentioned that the results produced by these two different measurements do not always produce a one-to-one correspondence. The biases due to localized influences or the drift of the radiosondes can contribute to the differences noted particularly in the upper altitudes. Further studies using the observational data from other locations near the equator are necessary to identify more details on the structure and phase propagation of the Kelvin waves. 
Acknowledgements. The first author (P. Kishore) deeply appreciates and is grateful to the Telecommunications Advancement Organization (TAO) of Japan, for their financial support. The second author (I. V. Subha Reddy) acknowledges the financial support from the Council of Scientific and Industrial Research (CSIR), India. The authors wish to thank National MST Radar Facility (NMRF), Gadanki and UGC-SVU Centre for MST Radar Applications, Sri Venkateswara University, Tirupati, for providing the necessary data for the present study.

Topical Editor U.-P. Hoppe thanks C. Jacobi for his help in evaluating this paper.

\section{References}

Canziani, P. O. and Holton, J. R.: Equatorial Kelvin wave variability during 1992 and 1993, J. Geophys. Res., 100D3, 5193-5202, 1995.

Dhaka, S. K., Krishna Murthy, B. V., Nagpal, O. P., Raghava Rao, R., Sasi, M. N., and Sundaresan, S.: A study of equatorial waves in the Indian zone, J. Atmos. Solar-Terr. Phys., 57, 1189-1202, 1995.

Fujiwara, M., Yamamoto, M. K., Hashiguchi, H., Horinouchi, T., and Fukao, S.: Turbulence at the tropopause due to breaking Kelvin waves observed by the Equatorial Atmosphere Radar, Geophys. Res. Lett., 304, 1171, doi:10.1029/2002GL016278, 2003.

Hildebrand, P. H. and Sekhon, R. S.: Objective determination of the noise level in the Doppler spectra, J. Appl. Meteorol., 13, 808$811,1974$.

Hirota, I.: Equatorial waves in the upper stratosphere and mesosphere in relation to the semiannual oscillation of the zonal wind, J. Atmos. Sci., 35, 714-722, 1978.

Hirota, I.: Kelvin waves in the equatorial middle atmosphere observed by the NIMBUS-5-SCR, J. Atmos. Sci., 36, 217-222, 1979.

Hitchman, M. H. and Leovy, C. B.: Evolution of the zonal mean state in the equatorial middle atmosphere during October 1978-May 1979, J. Atmos. Sci., 43, 3159-3176, 1986.

Holton, J. R. and Lindzen, R. S.: An updated theory for the quasibiennial cycle of the tropical atmosphere, J. Atmos. Sci., 29, 1076-1080, 1972.

Hooper, D. A., Arvelius, J., and Stebel, K.: Retrieval of atmospheric static stability from MST radar return signal power, Ann. Geophys., 22, 3781-3788, 2004,

SRef-ID: 1432-0576/ag/2004-22-3781.

Kishore, P.: Atmospheric studies using Indian MST radar - Winds and Turbulence parameters, Ph. D. Thesis, S. V. University, Tirupati, India, 1995.
Krishna Murthy, B. V., Satheesan, K., Parameswaran, K., Sasi, M. N., Ramkumar, G., Bhavanikumar, Y., Raghunath, K., and Krisnaiah, M.: Equatorial waves in temperature in the altitude range 4 to 70 km, Q. J. Royal Metorolo. Soc., 128, 819-837, 2002.

Lindzen, R. S. and Holton, J. R.: A Theory of the Quasi-Biennial Oscillation, J. Atmos. Sci., 25, 1095-1107, 1968.

Luo, Y., Manson, A. H., Meek, C. E., Thayaparan, T., MacDougall, J., and Hocking, W.: The 16-day wave in the mesosphere and lower thermosphere: simultaneous observations at Saskatoon $\left(52^{\circ} \mathrm{N}, 107^{\circ} \mathrm{W}\right)$ and London $\left(43^{\circ} \mathrm{N}, 81^{\circ} \mathrm{W}\right)$, Canada. J. Atmos. Solar-Terr. Phys., 64, 1287-1307, 2002.

Miyoshi, Y., Numerical simulation of the 5-day and 16-day waves in the mesopause region, Earth Planets Space, 51, 763-772, 1999.

Namboothiri, S. P., Kishore, P., and Igarashi, K.: Climatological studies of the quasi 16-day oscillations in the mesosphere and lower thermosphere at Yamagawa $\left(31.2^{\circ} \mathrm{N}, 130.6^{\circ} \mathrm{E}\right)$, Japan, Ann. Geophys., 20, 1-8, 2002,

SRef-ID: 1432-0576/ag/2002-20-1.

Randel, W. J.: Kelvin wave-induced trace constituent oscillations in the equatorial mesosphere, J. Geophys. Res., 95, 18 641-18 652, 1990.

Rao, P. B., Jain, A. R., Kishore, P., Balamuralidhar, P., Damle, S. H., and Viswanathan, G.: Indian MST radar, 1, System description and sample vector wind measurements in ST mode, Radio Sci., 30, 1125-1138, 1995.

Salby, M. L., Hartmann, D. L., Baily, P. L., and Gille, J. C.: Evidence of equatorial Kelvin modes in Nimbus-7 LIMS, J. Atmos. Sci., 41, 220-235, 1984.

Salby, M. L., Callaghan, P., Solomon, S., and Garcia, R. R.: Chemical fluctuations associated with vertically propagating equatorial Kelvin waves, J. Geophys. Res., 95, 20 491-20 505, 1990.

Sato, T.: Radar Principles, Handbook for MAP, edited by S. Fukao, Vol. 30, International School on Atmospheric Radar, 235-281, 1989.

Scargle, J. D.: Studies in astronomical time series analysis II, Statistical aspects of spectral analysis of unevenly spaced data, Astrophys. Journal, 263, 835-853, 1982.

Tsuda, T., Murayama, Y., Wiryosumarto, H., Harijono, S. W. B., and Kato, S.: Radiosonde observations of equatorial atmosphere dynamics over Indonesia, 1, Equatorial waves and diurnal tides, J. Geophys. Res., 99, 10 491-10 506, 1994a.

Tsuda, T., Murayama, Y., Wiryosumarto, H., Harijono, S. W. B., and Kato, S.: Radiosonde observations of equatorial atmosphere dynamics over Indonesia, 2, Characteristics of gravity waves, J. Geophys. Res., 99, 10 507-10 516, 1994b.

Wallace, J. M. and Kousky, V. E.: Observational evidence of Kelvin waves in the tropical stratosphere, J. Atmos. Sci., 25, 900-907, 1968. 